ARTICLE

https://doi.org/10.1038/s41467-019-13216-z

\title{
Abiotic synthesis of graphite in hydrothermal vents
}

\author{
Emily R. Estes (1D ${ }^{1,4 \star}$, Debora Berti (10) ${ }^{2,5}$, Nicole R. Coffey (10) ${ }^{1}$, Michael F. Hochella Jr. (1) 2,3, \\ Andrew S. Wozniak (1D ${ }^{1} \&$ George W. Luther III (1) ${ }^{1 *}$
}

Deciphering the origin, age, and composition of deep marine organic carbon remains a challenge in understanding the dynamics of the marine carbon cycle. In particular, the composition of aged organic carbon and what allows its persistence in the deep ocean and in sediment is unresolved. Here, we observe that both high and low temperature hydrothermal vents at the $9^{\circ} 50^{\prime} \mathrm{N} ; 104^{\circ} 17.5 \mathrm{~W}$ East Pacific Rise (EPR) vent field are a source for (sub) micron-sized graphite particles. We demonstrate that commonly applied analytical techniques for quantification of organic carbon detect graphite. These analyses thereby classify graphite as either dissolved or particulate organic carbon, depending on the particle size and filtration method, and overlook its relevance as a carbon source to the deep ocean. Settling velocity calculations indicate the potential for these (sub)micron particles to become entrained in the buoyant plume and distributed far from the vent fields. Thus, our observations provide direct evidence for hydrothermal vents acting as a source of old carbon to the deep ocean.

\footnotetext{
${ }^{1}$ School of Marine Science and Policy, University of Delaware, 700 Pilottown Road, Lewes, DE 19958, USA. ${ }^{2}$ Virginia Tech National Center for Earth and Environmental Nanotechnology (NanoEarth), 1991 Kraft Drive, Blacksburg, VA 24061, USA. ${ }^{3}$ Subsurface Science and Technology Group, Energy and Environment Directorate, Pacific Northwest National Laboratory, Richland, WA 99352, USA. ${ }^{4}$ Present address: International Ocean Discovery Program, Texas A\&M University, 1000 Discovery Drive, College Station, TX 77845, USA. ${ }^{5}$ Present address: Department of Oceanography, Texas A\&M University, 3146 TAMU, College Station, TX 77843, USA. *email: estes@iodp.tamu.edu; luther@udel.edu
} 
$\mathrm{D}$

eep marine organic carbon is a mixture of fresh material delivered from the surface and an aged component, the origin of which is undetermined ${ }^{1-4}$. Chemically recalcitrant carbon, terrestrial black carbon, carbon from resuspended sediments, and hydrothermally derived carbon are considered possible sources of this fraction, yet their relative contributions and ages remain unconstrained ${ }^{5-10}$. In sediment, black carbon is substantially older than concurrently deposited sedimentary organic carbon ${ }^{7,11}$. The age offset is hypothesized to represent the residence time of black carbon in the reservoir of deep dissolved organic carbon (DOC), prior to sorption onto particulate organic carbon (POC) and deposition in sediment or, alternately, aging in terrestrial soils prior to mobilization and deposition in marine sediment ${ }^{7}$. Although the black carbon described in these previous studies is hypothesized to derive from the terrestrial combustion of biomass, additional evidence exists for a hydrothermal contribution to deep DOC and POC $^{2,6}$ and to sedimentary black carbon $^{12}$. DOC synthesized in hydrothermal systems is depleted in ${ }^{14} \mathrm{C}$, as it likely forms either from mantle-derived dissolved inorganic carbon or dissolved seawater $\mathrm{CO}_{2}$ aged during circulation of ridge flank fluids. This depletion is observed for both abiotically synthesized hydrocarbons ${ }^{13}$ and chemoautotrophic synthesis of $\mathrm{DOC}^{6}$. Here, we identify (sub)micron-sized graphite particles emanating from five different focused and low temperature hydrothermal vent sites at the EPR $9^{\circ} 50^{\prime} \mathrm{N}$ vent field, providing an alternate source of old carbon to the deep ocean reservoir of DOC and POC. Common analytical approaches to measuring DOC and POC also access graphite (Supplementary Tables 2 and 3). Thus, with the exception of the few studies directly targeting measurement of graphite, this portion of the deep sea carbon reservoir has been previously unrecognized and its contribution not quantified robustly.

\section{Results and discussion}

Hydrothermal graphite occurrence and morphology. Particles were examined via transmission electron microscopy (TEM) and energy dispersive X-ray spectroscopy (EDS) (Table 1, Fig. 1). We found $\operatorname{sub}$ (micron) graphite in high-temperature end-member fluids and lower temperature samples in the hydrothermal plume within one meter of the chimney orifice, as well as in lower temperature vents (Table 1, Figs 1 and 2). Although we did not observe graphite in all samples, the absence of detection does not indicate that a vent was not emitting this material. Our TEM approach did not target detection and identification of graphite. Graphite was not observed in the end-member fluids $\left(361^{\circ} \mathrm{C}\right)$ captured at $\mathrm{P}$ Vent, but was found in an $\sim 15^{\circ} \mathrm{C}$ sample taken from higher in the hydrothermal plume (Fig. 1) at that site. At Biovent, graphite was observed in the end-member fluids $\left(335^{\circ} \mathrm{C}\right)$ and in a $15^{\circ} \mathrm{C}$ plume sample, but not in a $185^{\circ} \mathrm{C}$ sample from mid-height in the plume. One of the two samples analyzed from the low temperature Q Vent $\left(72{ }^{\circ} \mathrm{C}\right)$ contained graphite; graphite was not observed in the sample from Tica, a diffuse flow site. Overall, graphite was observed in 4 of the 10 samples examined (Table 1) and accounted for $6 \%$ of the area in 84 images of particles with known composition (including the more prevalent sulfide and silicate particles).

The majority of particles appear as aggregates of sheet-like structures with irregular edges (Fig. 1). This morphology matches the previous observation of graphite in sediment traps designed to collect fallout of vent material, suspended $50 \mathrm{~m}$ above the seafloor at distances of 200-300 m from the vent source at EPR $13^{\circ} \mathrm{N}^{8}$. This graphite was hypothesized to be hydrothermally derived and likewise consisted of large angular fragments overgrown with smaller platelets ${ }^{8}$. Exceptions in our samples include particle D (Biovent plume, $15^{\circ} \mathrm{C}$ ), which appears to be a greater number of small, aggregated fragments, and particle $\mathrm{E}$ (Biovent plume, $15^{\circ} \mathrm{C}$ ),

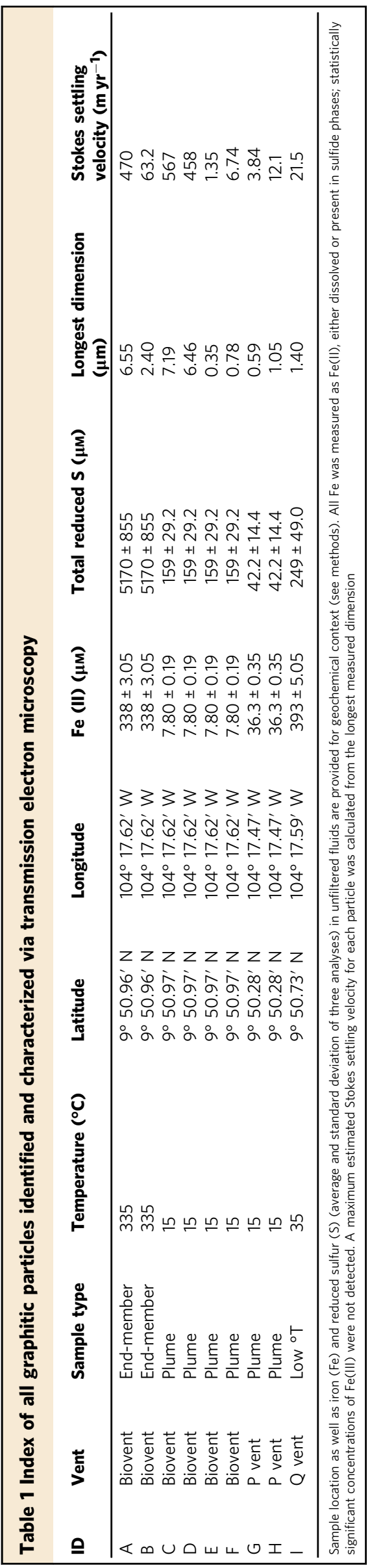




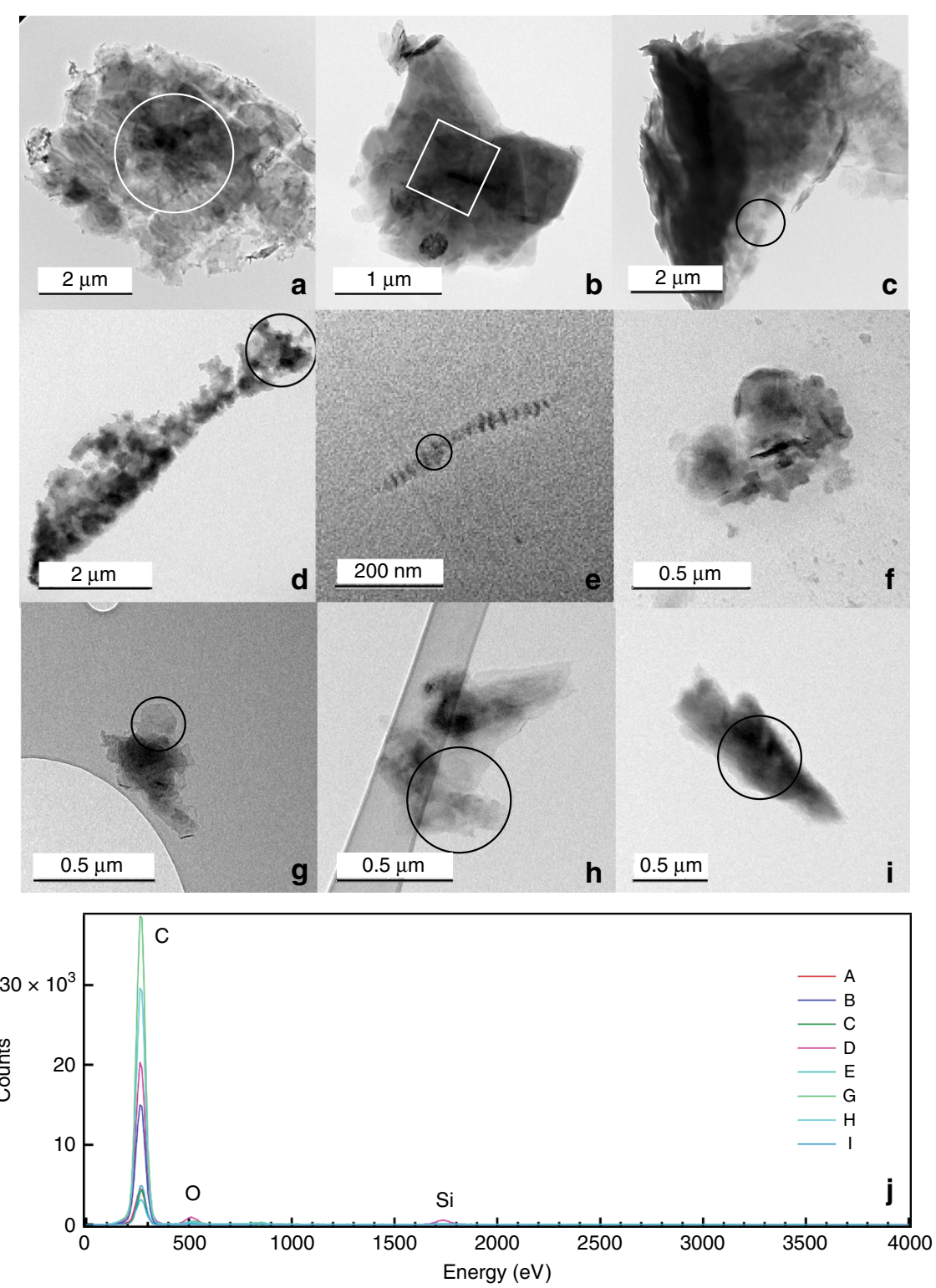

Fig. 1 Transmission electron microscopy (TEM) images of graphitic carbon particles. Particles were identified in high-temperature fluids (Biovent, $335^{\circ} \mathrm{C}$, a, b), hydrothermal plumes (within $1 \mathrm{~m}$ of the vent orifice, Biovent, $15^{\circ} \mathrm{C}, \mathbf{c}-\mathbf{f}, \mathrm{P}$ Vent, $15^{\circ} \mathrm{C}, \mathbf{g}-\mathbf{h}$ ), and diffuse flow (Q Vent, $\left.35^{\circ} \mathrm{C}, \mathbf{i}\right)$. Energy dispersive $\mathrm{X}$ ray spectroscopy (EDS) spectra $\mathbf{j}$ taken from marked areas on particles show a common composition of carbon with trace oxygen and silicon, which likely represent background from the TEM grid and detector (Supplementary Information Fig. 1). No EDS spectrum was acquired from the particle in $\mathbf{f}$

a long thread-like particle with alternating regions of high and low electron density (Fig. 1). Although our image is not well-resolved, this morphology is similar to polygonal graphite grains previously observed in metasediment and carbonate veins ${ }^{14}$. Rough particle edges and surfaces in the TEM images (Fig. 1) likely reflect microand nano-crystals not resolved at this magnification. Particle size ranges from $350 \mathrm{~nm}$ to 7.2 microns along the longest dimension (Table 1), smaller than the average particle size of 15 microns observed in the sediment traps deployed at the EPR $13^{\circ} \mathrm{N}$ vent field ${ }^{8}$. This size discrepancy may indicate that the smaller particles we observe are dispersed further from the vent site than the 200-300 $\mathrm{m}$ distances used in the previous work ${ }^{8}$. As we observe no larger particles, we posit that particles in this $<10$ micron size fraction account for the majority of the graphite flux and that this flux has been underestimated. It is possible although less likely that continued aggregation and growth during transport generates the larger particles observed previously.
Chemical composition and structure. All particles had nearidentical chemical compositions, consisting of carbon with very small amounts of oxygen, silicon, and nickel. All of these elements are likewise present in the TEM grid/blank; whereas nickel derives from the grid, there could be trace oxygen and silicon in the samples as well as the blanks (Fig. 1, Supplementary Fig. 1). In addition to EDS analysis, selected area electron diffraction (SAED) patterns were collected from seven of the nine particles to test for particle crystallinity (Fig. 2). Graphite sheets/layers tend to orient on the TEM grid, resulting in SAED patterns that only show reflections from (hk0) crystal planes. Therefore, for some particles (B, C, D, G), multiple SAED patterns were acquired after tilting the sample stage. Identification was further confirmed by high resolution TEM images (HRTEM) taken from particles edges (Supplementary Fig. 2). Measurements from SAED patterns and HRTEM match the d-spacings of graphite (American Mineralogist Crystal Structure Database, amcsd 14675) planes, varying from the 


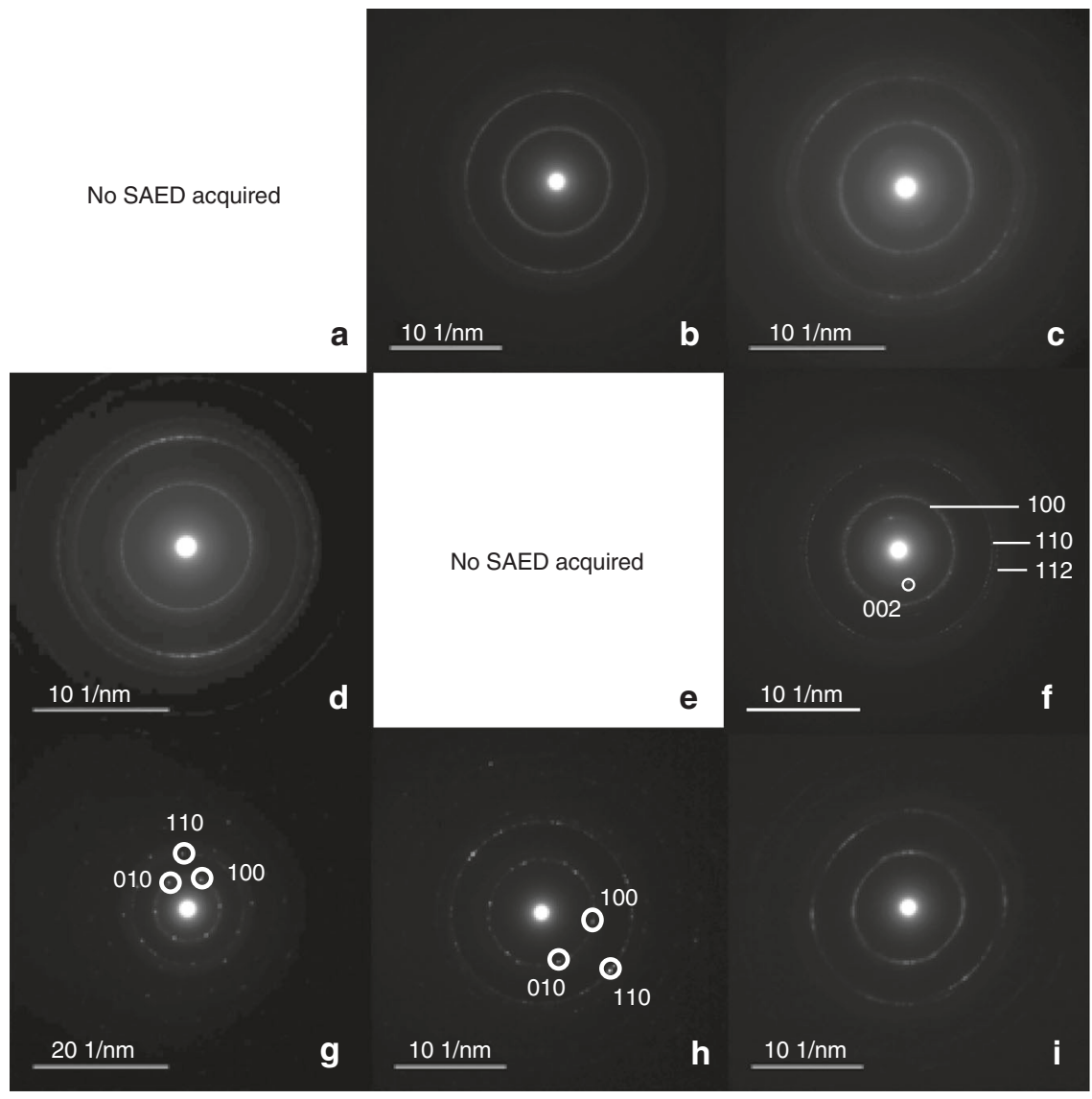

Fig. 2 Selected area electron diffraction (SAED) patterns acquired from the particles shown in Figure 1. The ring patterns generated from most particles indicate either turbostratic disorder or platy graphite layers randomly rotated and translated with respect to each other. Particles $f\left(B i o v e n t, 15^{\circ} \mathrm{C}\right)$ and $g$ and $\mathrm{h}\left(\mathrm{P}\right.$ Vent, $\left.15^{\circ} \mathrm{C}\right)$ display symmetric spot patterns that match well with graphite along [001], as shown in the image

AMCSD d-spacings by $<2.5 \%$ in all instances (Supplementary Table 1 and Fig. 2). The presence of spots and rings in all observed diffraction patterns indicates a mixture of both highly crystalline graphite and graphite layers randomly rotated and translated with respect to each other. We could not resolve whether the layers represent ultrathin single crystals with turbostratic disorder (compare with ref. ${ }^{15,16}$ ) or multiple, platy crystals stacked with differing planar orientations (compare with ref. ${ }^{16}$ ). However, the 002 reflection in some of the oriented SAED patterns is explained by curled edges visible in TEM and HRTEM images. Further, the close correspondence in d-spacing between our samples and the AMCSD pattern suggests disorder is primarily planar rather than turbostratic, the latter of which would result in increased dspacings ${ }^{15,16}$. In particular, the broad and diffuse rings of particles $\mathrm{B}, \mathrm{C}, \mathrm{D}$, and F reflect small crystal size on the order of $3-8 \mathrm{~nm}$ in addition to much larger crystals that generate the diffraction spots within the rings (Fig. 2). One SAED pattern acquired from an extremely thin region of particle $\mathrm{G}$ shows a symmetric spot pattern matching the graphite 001 zone axis; faint rings from less ordered, smaller crystals are visible underneath (Fig. 2).

Transport potential and implications for deep sea carbon. To estimate transport potential, we utilized the longest dimension of these irregular-shaped particles as the radius and assumed the density of graphite $\left(2.23 \mathrm{~g} \mathrm{~cm}^{-3}\right)$ to calculate Stokes settling velocities ranging between 1.35 and $567 \mathrm{~m} \mathrm{yr}^{-1}$ (Table 1). Less ordered or turbostratic graphite may be less dense and particles are flat and platy rather than spherical; consequently, our estimates of settling velocity are conservatively high. Compared with the 15 micron diameter sediment trap particles collected near the $13^{\circ} \mathrm{N}$
EPR vent field ${ }^{8}$, we expect that the smaller particles we observe in vent fluids at $9^{\circ} 50^{\prime} \mathrm{N}$ EPR will be entrained higher in the rising plume and transported significantly greater distances. Dissolved iron derived from hydrothermal vents along the southern EPR is transported distances $>4000 \mathrm{~km}$ from the vent source, likely stabilized by organic ligands ${ }^{17}$. The contribution of nanoparticulate phases to the operationally dissolved portion of hydrothermal plumes has not yet been quantified, although nanoparticulate pyrite is kinetically stable against oxidation over the timescales of transport $^{18}$. Pyrite nanoparticles with a $200 \mathrm{~nm}$ diameter have a Stokes settling velocity of $1.43 \mathrm{~m} / \mathrm{yr}^{18}$; comparable to the $1.35 \mathrm{~m} / \mathrm{yr}$ calculated for our smallest observed graphite particle. At the EPR $9^{\circ} 50^{\prime} \mathrm{N}$ vent field, seasonal deep-reaching mesoscale eddies may generate current velocities an order of magnitude higher than those in the southern EPR, up to $15 \mathrm{~cm} / \mathrm{s}^{19}$. Following this logic, we posit that hydrothermal graphite particles could disperse thousands of kilometers from the vent site.

Accordingly, $\mathrm{H} / \mathrm{C}$ vs $\mathrm{O} / \mathrm{C}$ van Krevelen plots identify carbonrich molecules that make up a small fraction of the deep Pacific $\mathrm{DOC}^{20}$ that could represent graphite or graphite altered by reactions with reactive oxygen species in the vent mixing zones. Circulation of seawater through basalt in the Juan de Fuca Ridge Flank results in an overall removal of DOC but the addition of aromatic compounds ${ }^{21}$, similar to the high aromaticity observed in fluids collected along the Mid-Atlantic Ridge ${ }^{22}$. These aromatics may derive from hydrothermal alteration of organic matter $^{23,24}$ or, in part, graphite alteration reactions. Further, over half of the black carbon in an Equatorial Pacific sediment sample at $8^{\circ} 55^{\prime} \mathrm{N}$ and $139^{\circ} 52^{\prime} \mathrm{W}(\sim 3900 \mathrm{~km}$ from our EPR site, but closer to other vent sites) consisted of either impure or highly 
organized graphite ${ }^{12}$, such as that observed here. The study describing this sedimentary graphite discounted a hydrothermal source given the distance and lack of metalliferous sediment; however, here, we characterize particles with the requisite transport potential, as determined from the Stokes settling velocity calculations. These particles may sink at distance from the vent source and not co-locate with metal enrichments.

Formation pathways. Graphite is known to form under hightemperature/high pressure conditions both from the reduction of $\mathrm{CO}$ or $\mathrm{CO}_{2}$ and graphitization of organic matter yet it has not previously been considered as a component of black smoker fluids. Here, we suggest that micron- and submicron-sized particles form in venting hot hydrothermal fluids or become mobilized from deeper deposits. Indeed, thermodynamic calculations indicate that graphite will form upon conductive cooling of representative hydrothermal end-member fluids ${ }^{25}$. The reaction pathway leading to the formation of hydrothermal graphite depends on the system geochemistry, but commonly proceeds via catalytic disproportionation of $\mathrm{CO}$ or reduction of $\mathrm{CO}$ and $\mathrm{CO}_{2}$ as described by Jedwab and Boulègue ${ }^{8}$ and Mathez and Delaney ${ }^{26}$.

$$
\begin{gathered}
2 \mathrm{CO} \rightarrow \mathrm{C}+\mathrm{CO}_{2} \text { (catalyzed by metal sulfides) } \\
\mathrm{CO}+\mathrm{H}_{2} \rightarrow \mathrm{C}+\mathrm{H}_{2} \mathrm{O} \text { (catalyzed by iron) } \\
\mathrm{CO}_{2} \rightarrow \mathrm{C}+\mathrm{O}_{2}
\end{gathered}
$$

Under the temperature and pressure regimes found in the vent systems considered here, $\mathrm{CO}_{2}$ will predominate over $\mathrm{CO}^{26}$. As concentrations of $\mathrm{Fe}$ and sulfide are elevated in hydrothermal fluids (mM), these species may nonetheless catalyze reactions of the trace concentrations of $\mathrm{CO}$. In basalts, elemental carbon phases occur along quench-produced microcracks, associated with metal sulfide spherules along the edges of vesicles, and in bubble inclusions ${ }^{26}$. These observed associations in conjunction with the abundance of $\mathrm{Fe}$ and sulfide in hydrothermal fluids implicate Eqs. (1) and (2) as likely reaction pathways although we do not discount Eq. (3). Graphitization of organic matter is another possible pathway for formation, although this reaction may require higher temperatures and pressures than these vent samples would have experienced as well as an initial carbonization step; the process is typically considered to require metamorphism ${ }^{27}$. In laboratory settings, however, iron ${ }^{28}$ and base metal $(\mathrm{Ni}, \mathrm{Fe}$, and Co) nanoparticles ${ }^{29}$ can catalyze graphitization and may likewise do so in the vent environment. Combustion or pyrolysis reactions, likewise, may produce black carbon and biochar compounds consisting of poorly ordered graphene and turbostratic graphite ${ }^{30}$. We observe several particles primarily composed of carbon but containing minor concentrations of nitrogen and oxygen that may be combustion or pyrolytic residues, representing organic matter undergoing alteration to graphite (Supplementary Fig. 3). These pathways are interesting targets for future investigations.

We demonstrate the presence of graphite in a range of hydrothermal fluids and suggest that vents globally are a source of graphite. Our observations thereby provide evidence for a significant but unconstrained flux of (sub)micron graphite to the ocean and sediment reservoirs of carbon. We demonstrate that this fraction may be misclassified as DOC or POC using common analytical techniques (Supplementary Tables 2 and 3) and emphasize the need for targeted measurements. As this hydrothermal graphite likely forms from mantle-derived carbon, we expect the particles to be highly ${ }^{14} \mathrm{C}$ depleted or radiocarbon-dead. These newly described (sub)micron-sized particles therefore confirm hydrothermal vents as a source of old carbon that can help explain age discrepancies in deep ocean DOC $^{2}$ and sedimentary carbon ${ }^{7}$.

\section{Methods}

Samples and sample processing. Samples of vent fluids were taken using the Human Operated Vehicle Alvin II and the titanium Major Samplers at multiple focused, low temperature, and diffuse flow sites along EPR $9^{\circ} 50^{\prime} \mathrm{N}$ vent field. Sample temperature was recorded using the ICL high-temperature probe attached to the Major Sampler. Samples were processed immediately shipboard, $\sim 2-4 \mathrm{~h}$ after collection. For each microscopy sample, between $20-80 \mathrm{~mL}$ of fluid was syringe-filtered onto a $0.2 \mu \mathrm{m}$ polycarbonate filter, rinsed with de-aerated $18 \mathrm{M} \Omega$ water, and dried under Ar. Volume filtered was a function of particle content; particle-rich fluids often clogged filters after $20 \mathrm{~mL}$ had passed through. Samples were preserved under Ar until analysis.

TEM and SAED. Particles on the polycarbonate filters were resuspended in distilled water by sonication. A drop of suspension was deposited on ultrathin $\mathrm{C}$ or lacey C supported nickel TEM grids and allowed to dry. The grids were analyzed in a JEOL JEM-2100 analytical TEM, operated at $200 \mathrm{keV}$. This TEM is equipped with a $60 \mathrm{~mm}^{2}$ window, JEOL EX-230 Silicon Drift Detector (SDD) that allows acquisition of EDS spectra with a spatial resolution of $3 \mathrm{~nm}$ in STEM mode, and in the range of 5-10's of nanometers in parallel illumination TEM mode. Images were acquired at different magnifications to characterize morphology and size of particles. SAED patterns were acquired from representative particles and analyzed using Gatan Digital Micrograph software (GMS 3) to measure crystalline features. EDS spectra were collected from the same regions. Minerals were identified based on both EDS spectra and SAED patterns.

Dissolved carbon analyses. To prepare a graphite dissolved carbon standard, $0.0665 \mathrm{~g}$ of graphite (Ward's Science) was suspended in $1 \mathrm{~L}$ of filtered seawater (FSW) collected offshore of Delaware. Homogeneity and particle disaggregation were ensured by sonication. In triplicate, $60 \mathrm{~mL}$ of the graphite/FSW mixture were vacuum filtered using pre-combusted GF/F filters (Whatman, $0.7 \mu \mathrm{m}$ nominal pore size). Filtrate was immediately poured into $30 \mathrm{~mL}$ vials, acidified using $2 \mathrm{M} \mathrm{HCl}$, and analyzed on a Shimadzu TOC-V CPH Total Organic Carbon Analyzer. The instrument was operated at $680{ }^{\circ} \mathrm{C}$ using UHP air as the carrier gas and calibrated using a five-point standard curve created with a potassium hydrogen phthalate (LabChem) standard. Concentrations were determined using the best three of five injections per sample. Acidified FSW samples (no graphite added) were analyzed in the same way and in the presence of pre-combusted glass beads, and graphite suspended samples were compared with these control samples to determine whether graphite was detected in the operationally-defined DOC. The difference in DOC concentrations between FSW and FSW with glass bead samples was not statistically different than $0(0.6 \pm 4 \mu \mathrm{M} ; n=4)$. A Deep Sea Reference (Hansell Laboratory, DSR Lot \# 07-07, 41-45 $\mathrm{M}$ DOC) was also run as a quality control. A value of $47.8 \pm 2.0 \mu \mathrm{M}, n=3$ was measured for this reference standard.

Particulate carbon analyses. Graphite (Ward's Science) standard was dried in an oven at $54{ }^{\circ} \mathrm{C}$ for $24 \mathrm{~h}$ and stored in a desiccator until analysis. The graphite was weighed into tin capsules (Elemental Microanalysis). NIST Standard Reference Material 2975 Diesel Particulate Matter (Industrial Forklift, reported previously as $84 \pm 9 \%$ OC $^{25}$ and $80 \pm 14 \%$ OC $^{26}$ ) was prepared in the same manner as a quality control. These samples were then analyzed on a Costech ECS 4010 Elemental Combustion System CHNS-O operated in CHN mode with two furnaces. The first furnace contained a chromium oxide and silver cobaltous/cobaltic oxide column held at $980^{\circ} \mathrm{C}$; the second furnace contains a reduced copper wire column and is held at $650^{\circ} \mathrm{C}$. He was used as a carrier gas $(100 \mathrm{~mL} / \mathrm{min})$ and $\mathrm{O}_{2}$ flowrate was 25 $\mathrm{mL} / \mathrm{min}$. The instrument was calibrated using an eight-point calibration curve created using both reagent-grade phenylalanine (Sigma Aldrich) and ethylenediaminetetraacetic acid (Sigma Aldrich) standards. SRM-2975 was measured as $81.5 \pm 7.1 \%$ OC, $n=3$, in agreement with previously published analyses ${ }^{31,32}$.

Stokes settling velocities. Maximum Stokes settling velocities were calculated from the longest particle dimension and a density of $2.23 \mathrm{~g} \mathrm{~cm}^{-3}$, assuming a spherical particle and following Yücel et al. ${ }^{18}$ and Schwarzenbach et al. ${ }^{33}$. We consider this calculation an overestimate as particles are not spherical and are likely less dense if less well-ordered than fully crystalline graphite. Particle dimensions were determined using the Fiji software package ${ }^{34}$. Under laminar flow, the equation is written as:

$$
V=g * D^{2} *\left(d_{p}-d_{m}\right) /(18 * v)
$$

$V$ : settling velocity $\left(\mathrm{m} \mathrm{s}^{-1}\right)$

$g$ : gravitational acceleration, $9.8 \mathrm{~m} \mathrm{~s}^{-2}$

$D$ : particle diameter $(\mathrm{m})$

$d_{\mathrm{p}}$ : particle density, $2230 \mathrm{~kg} \mathrm{~m}^{-3}$ for graphite

$d_{\mathrm{m}}$ : medium density, $1029 \mathrm{~kg} \mathrm{~m}^{-3}$ for seawater

$v$ : viscosity of seawater, $1.88 \times 10^{-3} \mathrm{~kg} \mathrm{~m}^{-1} \mathrm{~s}^{-1}$

Iron and sulfur concentrations. Total iron and reduced sulfur in unfiltered fluids were analyzed spectrophotometrically using the ferrozine and acid volatile sulfides/ chromium-reducible sulfides (AVS/CRS) methods, respectively. These methods are described in Findlay et al. ${ }^{35}$. 


\section{Data availability}

TEM images, SAED patterns, and EDS data are available from the authors upon request.

Received: 10 May 2019; Accepted: 28 October 2019;

Published online: 15 November 2019

\section{References}

1. Hansell, D. A. Recalcitrant dissolved organic carbon fractions. Ann. Rev. Mar. Sci. 5, 421-445 (2013).

2. Druffel, E. R. M. \& Griffin, S. Radiocarbon in dissolved organic carbon of the South Pacific Ocean. Geophys. Res. Lett. 42, 4096-4101 (2015).

3. Walker, B. D., Beaupré, S. R., Guilderson, T. P., McCarthy, M. D. \& Druffel, E. R. M. Pacific carbon cycling constrained by organic matter size, age and composition relationships. Nat. Geosci. 9, 888-891 (2016).

4. Williams, P. M. \& Druffel, E. R. M. Radiocarbon in dissolved organic matter in the central North Pacific Ocean. Nature 330, 246-248 (1987).

5. Jiao, N. et al. Microbial production of recalcitrant dissolved organic matter: long-term carbon storage in the global ocean. Nat. Rev. Microbiol. 8, 593-599 (2010).

6. McCarthy, M. D. et al. Chemosynthetic origin of 14C-depleted dissolved organic matter in a ridge-flank hydrothermal system. Nat. Geosci. 4, 32-36 (2011).

7. Coppola, A. I., Ziolkowski, L. A., Masiello, C. A. \& Druffel, E. R. M. Aged black carbon in marine sediments and sinking particles. Geophys. Res. Lett. 41, 2427-2433 (2014).

8. Jedwab, J. \& Boulègue, J. Graphite crystals in hydrothermal vents. Nature 310, 41-43 (1984)

9. Hansell, D., Carlson, C., Repeta, D. \& Schlitzer, R. Dissolved organic matter in the ocean: a controversy stimulates new insights. Oceanography 22, 202-211 (2009).

10. Beaupré, S. R. \& Druffel, E. R. M. Constraining the propagation of bombradiocarbon through the dissolved organic carbon (DOC) pool in the northeast Pacific Ocean. Deep Sea Res. Part I Oceanogr. Res. Pap. 56, 1717-1726 (2009).

11. Masiello, C. A. \& Druffel, E. R. M. Black carbon in deep-sea sediments. Science 280, 1911-1913 (1998).

12. Haberstroh, P. R. et al. Chemical composition of the graphitic black carbon fraction in riverine and marine sediments at sub-micron scales using carbon X-ray spectromicroscopy. Geochim. Cosmochim. Acta 70, 1483-1494 (2006).

13. Proskurowski, G. et al. Abiogenic hydrocarbon production at lost city hydrothermal field. Science 319, 604-607 (2008).

14. Ohtomo, Y., Kakegawa, T., Ishida, A., Nagase, T. \& Rosing, M. T. Evidence for biogenic graphite in early Archaean Isua metasedimentary rocks. Nat. Geosci. 7, 25-28 (2014).

15. Binder, C. et al. Structure and properties of in situ-generated two-dimensional turbostratic graphite nodules. Carbon N. Y. 124, 685-692 (2017).

16. Groopman, E., Nittler, L. R., Bernatowicz, T. \& Zinner, E. NanoSIMS, TEM, and XANES studies of a unique presolar supernova graphite grain. Astrophys. J. 790, 9 (2014).

17. Resing, J. A. et al. Basin-scale transport of hydrothermal dissolved metals across the South Pacific Ocean. Nature 523, 200-203 (2015).

18. Yücel, M., Gartman, A., Chan, C. S. \& Luther, G. W. Hydrothermal vents as a kinetically stable source of iron-sulphide-bearing nanoparticles to the ocean. Nat. Geosci. 4, 367-371 (2011).

19. Adams, D. K. et al. Surface-generated mesoscale eddies. Science 332, 580-583 (2011).

20. Bercovici, S. K. et al. Aging and molecular changes of dissolved organic matter between two deep oceanic end-members. Glob. Biogeochem. Cycles 32, 1449-1456 (2018).

21. Lin, H. T., Repeta, D. J., Xu, L. \& Rappé, M. S. Dissolved organic carbon in basalt-hosted deep subseafloor fluids of the Juan de Fuca Ridge flank. Earth. Planet. Sci. Lett. 513, 156-165 (2019).

22. Rossel, P. E. et al. Thermally altered marine dissolved organic matter in hydrothermal fluids. Org. Geochem. 110, 73-86 (2017)

23. Simoneit, B. R. T. Aqueous high-temperature and high-pressure organic geochemistry of hydrothermal vent systems. Geochim. Cosmochim. Acta 57, 3231-3243 (1993).

24. Dittmar, T. \& Koch, B. P. Thermogenic organic matter dissolved in the abyssal ocean. Mar. Chem. 102, 208-217 (2006).

25. Bowers, T. S., Von Damm, K. L. \& Edmond, J. M. Chemical evolution of midocean ridge hot springs. Geochim. Cosmochim. Acta 49, 2239-2252 (1985).

26. Mathez, E. A. \& Delaney, J. R. The nature and distribution of carbon in submarine basalts and peridotite nodules. Earth. Planet. Sci. Lett. 56, 217-232 (1981).

27. Buseck, P. R. \& Beyssac, O. From organic matter to graphite: graphitization. Elements 10, 421-426 (2014).
28. Thompson., E., Danks, A. E., Bourgeois, L. \& Schnepp, Z. Iron-catalyzed graphitization of biomass. Green. Chem. 17, 551-556 (2015).

29. Hoekstra, J. et al. Base metal catalyzed graphitization of cellulose: a combined Raman spectroscopy, temperature-dependent X-ray diffraction and highresolution transmission electron microscopy study. J. Phys. Chem. C. 119, 10653-10661 (2015).

30. Keiluweit, M., Nico, P. S., Johnson, M. G. \& Kleber, M. Dynamic molecular structure of plant biomass-derived black carbon (biochar). Environ. Sci. Technol. 44, 1247-1253 (2010).

31. Elmquist, M. et al. Distinct oxidative stabilities of char versus soot black carbon: Implications for quantification and environmental recalcitrance. Global Biogeochem. Cycles. 20: 0.1029/2005GB002629 (2006).

32. Han, Y. et al. Evaluation of the thermal/optical reflectance method for discrimination between char- and soot-EC. Chemosphere 69, 569-574 (2007)

33. Schwarzenbach, R. P., Gschwend, P. M. \& Imboden, D. M. Environmental Organic Chemistry. (John Wiley and Sons, Inc. 1993).

34. Schindelin, J. et al. Fiji: An open-source platform for biological-image analysis. Nat. Methods 9, 676-682 (2012).

35. Findlay, A. J., Estes, E. R., Gartman, A., Yucel, M., Kamyshny Jr., A., \& Luther III, G. W. Iron and sulfide nanoparticle formation and transport in nascent hydrothermal vent plumes. Nat. Commun. 10, 1597 (2019).

\section{Acknowledgements}

This work was supported by NSF OCE Marine Geology and Geophysics grant 1558712 awarded to George W. Luther. We thank the Captain and crew of the R/V Atlantis as well as the Expedition Leader, pilots, and crew of the HOV Alvin for their knowledge and facilitation of sample collection. We thank the science party of AT37-11 for additional assistance in handling the titanium Major Samplers. Sunita Shah-Walter read and provided valuable feedback on drafts of the manuscript. This work used shared facilities at the Virginia Tech National Center for Earth and Environmental Nanotechnology Infrastructure (NanoEarth), a member of the National Nanotechnology Coordinated Infrastructure (NNCI), supported by NSF (ECCS 1542100).

\section{Author contributions}

E.R.E. and G.W.L. III designed the study. G.W.L. III served as chief scientist on AT37-11; E.R.E. conducted shipboard sampling of hydrothermal vent fluids and particulates. D.B. and M.F.H. Jr conducted TEM, EDS, and SAED analyses and preliminary data processing and interpretation. A.S.W. and N.R.C. designed and conducted POC and DOC experiments with the graphite. E.R.E and G.W.L. III wrote the manuscript. All authors contributed to the interpretation of results and editing of the manuscript.

\section{Competing interests}

The authors declare no competing interests.

\section{Additional information}

Supplementary information is available for this paper at https://doi.org/10.1038/s41467019-13216-z.

Correspondence and requests for materials should be addressed to E.R.E. or G.W.L.III

Peer review information Nature Communications thanks the anonymous reviewer(s) for their contribution to the peer review of this work. Peer reviewer reports are available.

Reprints and permission information is available at http://www.nature.com/reprints

Publisher's note Springer Nature remains neutral with regard to jurisdictional claims in published maps and institutional affiliations.

Open Access This article is licensed under a Creative Commons Attribution 4.0 International License, which permits use, sharing, adaptation, distribution and reproduction in any medium or format, as long as you give appropriate credit to the original author(s) and the source, provide a link to the Creative Commons license, and indicate if changes were made. The images or other third party material in this article are included in the article's Creative Commons license, unless indicated otherwise in a credit line to the material. If material is not included in the article's Creative Commons license and your intended use is not permitted by statutory regulation or exceeds the permitted use, you will need to obtain permission directly from the copyright holder. To view a copy of this license, visit http://creativecommons.org/ licenses/by/4.0/

(C) The Author(s) 2019 